\title{
AVALIAÇÃO NA LINGUAGEM: CONFIGURAÇÃO E FUNÇÃO DO SUBSISTEMA DE ENGAJAMENTO EM NOTÍCIAS DE POPULARIZAÇÃO CIENTÍFICA
}

\author{
Cristina dos Santos Lovato*
}

\begin{abstract}
RESUMO: Sob o aporte teórico do Sistema de Avaliatividade (MARTIN; WHITE, 2005), este trabalho tem como objetivo analisar a configuração e a função do Subsistema de Engajamento em 15 notícias de popularização científica. Realizamos uma análise qualiquantitativa, mapeando e classificando os indices linguísticos que constituem esse subsistema. Os resultados indicam que, nas notícias analisadas, o Subsistema de Engajamento é materializado por meio da mobilização dos recursos linguísticos que realizam a expansão dialógica. Esses recursos produzem um efeito de imparcialidade, sugerindo uma tentativa de isenção por parte da voz autoral em relação ao conteúdo das suas proposições e das proposições das vozes não autorias inseridas nas notícias.
\end{abstract}

PALAVRAS-CHAVE: Avaliação na linguagem - Subsistema de Engajamento - Notícias de popularização científica

ABSTRACT: From the theoretical approach of the Appraisal System (MARTIN; WHITE, 2005), this work aims to analyze the configuration and the function of the Engagement Subsystem in 15 scientific popularization news. We conducted a quali-quantitative analysis, mapping and classifying the linguistic indices that constitute this subsystem. The results indicate that the Engagement Subsystem in the news is materialized by the mobilization of the linguistic resources that perform the dialogic expansion. These resources produce an impartial effect, suggesting an exemption attempt from the authorial voice in relation to the content of his/her statements and the statements of the non-authorial voices brought into the news.

KEY-WORDS: Appraisal in language - Engagement Subsystem - Scientific popularization news

\section{CONTEXTUALIZAÇÃO}

Este trabalho é parte de um projeto guarda-chuva intitulado Análise crítica de gêneros com foco em artigos de popularização da ciência (MOTTA-ROTH, 2007) desenvolvido no Laboratório de Pesquisa e Ensino de Leitura e Redação (Labler), da Universidade Federal de Santa Maria/RS. Sob a ótica da Linguística Aplicada, as pesquisas visam à investigação e à explanação de questões relativas aos usos da linguagem em contextos sociais específicos, promovendo reflexões acerca das condições de produção, distribuição e consumo de textos midiáticos de popularização da ciência.

\footnotetext{
* Doutoranda do Programa de Pós-Graduação em Letras da Universidade Federal de Santa Maria. Bolsista CAPES./ cristina.lovato@yahoo.com.br
} 
O objeto de análise dos trabalhos desenvolvidos nesse projeto é o gênero notícia de popularização científica (doravante notícia de PC), definido por Motta-Roth e Marcuzzo (2010, p. 518) como

\begin{abstract}
textos publicados pela mídia (autodefinida) de PC, que relatam a realização de uma pesquisa recente e de interesse para a comunidade-alvo da publicação e que apresentam duas partes: o sumário (a manchete / o título e o lide) e a história propriamente dita,com 1) a situação, incluindo a) os episódios (os eventos principais ligados à pesquisa e suas consequências) e b) o pano de fundo (o contexto - circunstâncias e eventos prévios - e a história); e 2) os comentários, incluindo as reações verbais e as conclusões (as expectativas, as avaliações e o significado da pesquisa para a comunidade).
\end{abstract}

Ao convergirem para esse mesmo ponto, o gênero notícia de PC, os trabalhos fazem um mapeamento do discurso de popularização da ciência nesses textos, buscando apresentar uma análise sistematizada e um entendimento dessa prática social, a fim de subsidiar um ensino que promova uma educação de qualidade, oferecendo a possibilidade de emancipação cultural e social dos sujeitos envolvidos nos processos de ensino e aprendizagem.

Tomando como referência os estudos de Martin e White (2005), sobre a avaliatividade na linguagem, neste trabalho, fazemos um recorte em parte do corpus do projeto guarda-chuva e analisamos a configuração e a função do Subsistema de Engajamento em 15 notícias de PC, publicadas pelas revistas especializadas em jornalismo científico: Ciência Hoje, Galileu e Scientific American Brasil.

A seguir, revisamos o Sistema de Avaliatividade (Martin; White, 2005) e descrevemos o Subsistema de Engajamento. Em seguida, explicamos a metodologia utilizada para a realização do estudo. Por fim, apresentamos e discutimos os resultados obtidos.

\title{
SISTEMA DE AVALIATIVIDADE
}

Martin e White (2005) apresentam um inventário de recursos linguísticos para a análise da avaliatividade na linguagem. Os autores buscam explicitar o modo como a linguagem é utilizada para avaliar, adotar posicionamento, julgar atos e eventos/coisas concretas por meio do elogio e da censura (CABRAL; BARROS, 2006, p. 725). A Figura 1 ilustra o Sistema de Avaliatividade.

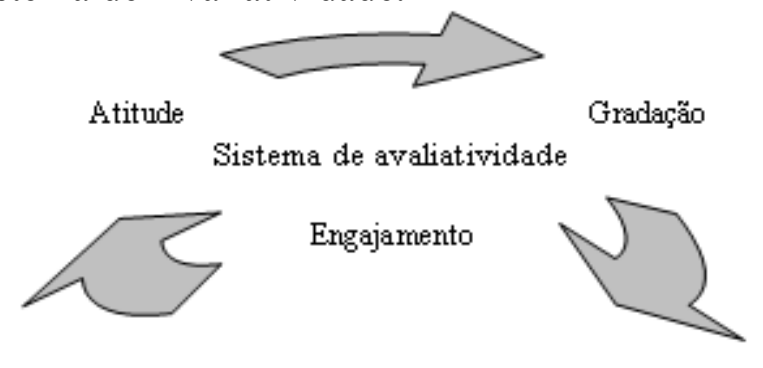

Figura 1 - Sistema de Avaliatividade (MOTTA-ROTH; LOVATO, no prelo).

Cadernos do IL. Porto Alegre, n. ${ }^{\circ} 38$, junho de 2009. p. 155-165. http://www.seer.ufrgs.br/cadernosdoil/ 
O Sistema de Avaliatividade é composto por três subsistemas que operam paralelamente: Atitude, Gradação e Engajamento. O Subsistema de Atitude está relacionado aos sentimentos positivos ou negativos do falante/escritor, incluindo reações emocionais, julgamentos de comportamento e de avaliação estética de coisas, de situações e de seres (MARTIN; WHITE, 2005, p. 35). É subdividido em Afeto (emoção - reações emocionais perante situações/coisas/seres vivos), Julgamento (ética avaliações sobre o comportamento de pessoas e instituições, em termos de capacidade, normalidade, tenacidade, veracidade e propriedade) e Apreciação (estética - avaliações de caráter estético acerca de coisas/situações/seres vivos). O Subsistema de Gradação diz respeito ao modo como os falantes/escritores alteram a força e o foco de suas avaliações e pode ocorrer tanto para intensificar, quanto para minimizar uma reação emocional ou um julgamento. Por fim, o Subsistema de Engajamento concerne ao modo pelo qual a voz autoral se posiciona em relação ao seu enunciado e ao enunciado de outros autores sociais, conforme será mais bem explicado na seção que segue.

\section{SUBSISTEMA DE ENGAJAMENTO}

O Subsistema de Engajamento está calcado nas noções de Dialogismo e de Heteroglóssia propostas por Bakhtin (Cf. 2004, por exemplo), visto que tem como objetivo descrever o modo como falantes/escritores reconhecem discursos anteriores aos seus e de que maneira se engajam ou não com esses enunciados. Segundo Martin e White (2005, p. 95), o Subsistema de Engajamento busca vislumbrar 1) a negociação de significado entre enunciador e enunciatário, em termos de Alinhamento e Desalinhamento, de acordo com as posições referenciadas no/pelo texto, e 2) como essa negociação interfere na relação que o texto constrói entre o enunciador e o enunciatário.

Esse subsistema é dividido em duas orientações: expansão dialógica e contração dialógica. Na expansão dialógica, o falante/escritor apresenta o tópico desenvolvido como uma questão em aberto, produzindo um efeito de convite a alternativas dialógicas ou posicionamentos alternativos. São palavras que a voz autoral utiliza para indicar que aquela posição é uma dentre um leque de possibilidades. Pode ocorrer por acolhimento ou atribuição. $\mathrm{O}$ acolhimento engloba os significados que o falante/escritor alcança por meio de declarações de probabilidade. É sinalizado léxicogramaticalmente por verbos modais (parece, poderia, deveria), adjuntos modais (talvez, provavelmente ); atributos modais (é possível que, é provável que); circunstâncias (em minha opinião) e via certos verbos mentais (eu suspeito que, eu acho que, eu acredito que, estou convencido que ) (MARTIN; WHITE, 2005, p. 104-105).

A atribuição inclui formulações que dissociam a proposição da voz autoral interna, atribuindo-a a uma voz não autoral por meio da utilização do relato e da citação. Pode ocorrer por reconhecimento e por distanciamento. A atribuição por reconhecimento compreende os significados expressos por processos verbais considerados neutros, utilizados simplesmente para reportar as palavras de outras pessoas, tais como os processos dizer, relatar, declarar e expressões como de acordo

Cadernos do IL. Porto Alegre, n. ${ }^{\text {o } 38, ~ j u n h o ~ d e ~ 2009 . ~ p . ~ 155-165 . ~}$ http://www.seer.ufrgs.br/cadernosdoil/ 
com e segundo X (MARTIN; WHITE, 2005, p.112). A atribuição por distanciamento estabelece uma separação explícita da voz autoral interna em relação às declarações das vozes não autorais inseridas no texto. É sinalizada principalmente pelo emprego de citações e de proposições projetas pelos verbos defender, alegar e garantir, por exemplo (MARTIN; WHITE, 2005, p.113).

A contração dialógica inclui formulações que reduzem o espaço dialógico. É produzida por significados que invocam algum enunciado anterior, ou uma posição, para diretamente refutá-la. Os significados contrativos são divididos em refutação e declaração (MARTIN; WHITE, 2005, p.117). A refutação inclui significados que invocam algum enunciado anterior ou alguma posição alternativa, para rejeitá-la. Pode ocorrer por negação e contestação. A negação é um recurso utilizado para introduzir uma posição alternativa positiva no diálogo, engajar-se com ela, para rejeitá-la na sequência. É sinalizada pelos advérbios de negação não, nem, nunca e jamais, por exemplo. A contestação engloba as proposições que substituem ou suplantam outras. É realizada léxico-gramaticalmente pelas conjunções embora e mas, por exemplo. Por fim, a declaração envolve a ênfase autoral ou intervenções/interpelações explícitas por parte do falante/escritor (Eu afirmo..., Os fatos em questão são..., A verdade é que..., por exemplo). Pode ocorrer por concordância (com certeza, naturalmente, certamente), endosso (voz não autoral correta, válida e confiável - mostra, demonstra, comprova, confirma e aponta -) e pronunciamento (intervenção autoral explícita - Eu defendo..., Os fatos em questão são..., Podemos concluir que...) (MARTIN; WHITE, 2005, p. 121122). A Figura 2 ilustra o Subsistema de Engajamento.

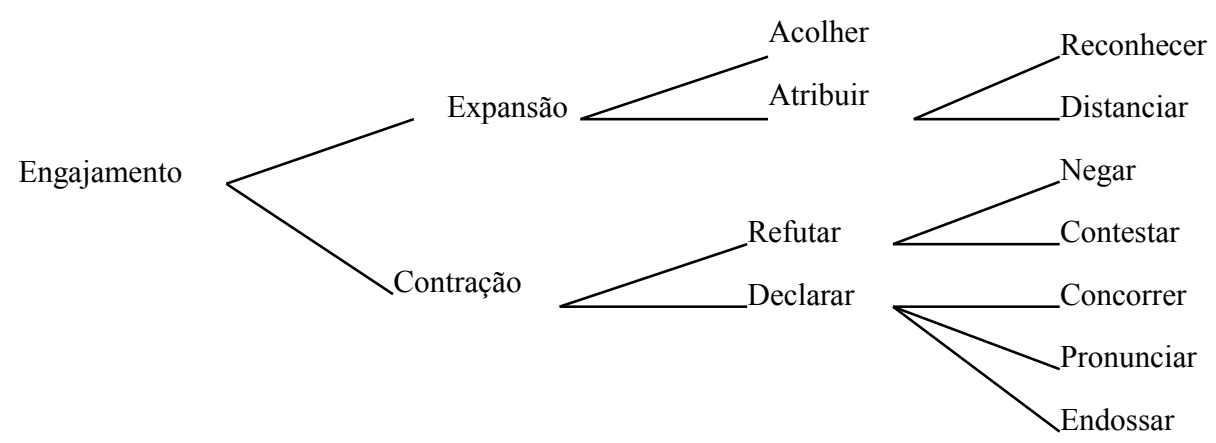

Figura 2 - Subsistema de Engajamento (Martin; White. 2005).

Com base no inventário de categorias linguísticas descritas nessa seção, mapeamos e classificamos os índices linguísticos que realizam o Subsistema de Engajamento nas notícias do corpus. Na sequência, são detalhamos os procedimentos metodológicos empregados para a realização deste estudo. 


\section{METODOLOGIA}

O presente trabalho é de cunho qualiquantitativo. O corpus é composto por 15 notícias de popularização científica sobre tópicos de saúde, extraídas dos sites das revistas Ciência Hoje (CH), Galileu (GL) e Scientific American Brasil (SCIAMB) (Quadro 1).

\begin{tabular}{|l|l|l|}
\hline \multicolumn{1}{|c|}{ CH } & \multicolumn{1}{|c|}{ GL } & \multicolumn{1}{|c|}{ SCIAMB } \\
\hline \#1 Ameaça invisível & $\begin{array}{l}\text { \#1Camiseta suja de mulher } \\
\text { deixa homem excitado }\end{array}$ & $\begin{array}{l}\text { \#1 Novos instrumentos permitem biópsias } \\
\text { virtuais para detecção do câncer }\end{array}$ \\
\hline $\begin{array}{l}\text { \#2 Boa forma física e } \\
\text { intelectual }\end{array}$ & $\begin{array}{l}\text { \#2 Chefe incompetente é mais } \\
\text { agressivo, indicam estudos }\end{array}$ & $\begin{array}{l}\text { \#2 Profissionais não especializados } \\
\text { viabilizam tratamento eficaz da ansiedade }\end{array}$ \\
\hline $\begin{array}{l}\text { \#3 Esperança contra o } \\
\text { câncer em óleos vegetais }\end{array}$ & $\begin{array}{l}\text { \#3 Cientistas estudam como } \\
\text { vermes podem inibir alergias }\end{array}$ & $\begin{array}{l}\text { \#3Contato com fumaça de cigarro afeta } \\
\text { saúde de fetos }\end{array}$ \\
\hline $\begin{array}{l}\text { \#4 Guerra Microbiana } \\
\text { \#4 Genes melhores' podem } \\
\text { fazer mulher ter mais parceiros }\end{array}$ & $\begin{array}{l}\text { \#4 Coração pode revelar informações } \\
\text { sobre a saúde dos rins }\end{array}$ \\
\hline $\begin{array}{l}\text { \#5 O usuário padrão de } \\
\text { maconha }\end{array}$ & $\begin{array}{l}\text { \#5 Hormônio ajuda menino a a } \\
\text { gostar mais de bola }\end{array}$ & $\begin{array}{l}\text { \#5 Criado mosquito imune ao parasita da } \\
\text { malária }\end{array}$ \\
\hline
\end{tabular}

\section{Quadro 1 - Notícias do corpus}

Cada notícia foi rotulada com um código composto pelas iniciais da revista de onde foram extraídas e enumeradas de um a cinco.

\section{PROCEDIMENTOS DE ANÁLISE}

O texto das notícias foi parcelado em blocos; na sequência, procedemos ao mapeamento dos elementos linguísticos, que realizam o Subsistema de Engajamento textualmente, e à marcação manual dessas ocorrências. Como critério de análise, foi estabelecido que seria analisado somente o posicionamento do jornalista em relação as suas proposições e às proposições das vozes não autorias inseridas nas notícias. A partir dessa marcação, as realizações desse subsistema foram enquadradas para classificação e tabuladas para quantificação. Neste trabalho, exemplificamos e discutimos somente as categorias mais recorrentes.

Na próxima seção, os dados triangulados nesses procedimentos são discutidos por meio da exposição dos percentuais obtidos e exemplos extraídos das notícias do corpus.

\section{RESULTADOS E DISCUSSÃO}

Os resultados quantitativos revelam a predominância da expansão dialógica nas notícias analisadas. Das 79 ocorrências do Subsistema de Engajamento nas notícias da 
CH: $65 \%$ são relativas à expansão dialógica, conforme demonstra a Tabela 1 . Dessa forma, o tópico desenvolvido na notícia é apresentado como uma questão em aberto.

\begin{tabular}{|c|c|c|c|c|c|c|c|c|c|}
\hline \multirow{3}{*}{$\begin{array}{c}\text { Ciência Hoje } \\
\text { On-line }\end{array}$} & \multicolumn{3}{|c|}{ Expansão dialógica } & \multicolumn{5}{|c|}{ Contração dialógica } & \multirow{3}{*}{$\stackrel{\pi}{\circ}$} \\
\hline & \multirow{2}{*}{ Acolher } & \multicolumn{2}{|c|}{ Atribuição } & \multicolumn{2}{|c|}{ Refutar } & \multicolumn{3}{|c|}{ Declarar } & \\
\hline & & Reconhecer & Distanciar & Negar & Contestar & Concorrer & Pronunciar & Endossar & \\
\hline $\mathrm{CH \# 1}$ & 01 & 05 & 06 & - & 02 & 01 & - & 07 & 22 \\
\hline $\mathrm{CH} \# 2$ & 01 & 04 & 05 & - & 02 & - & - & 04 & 16 \\
\hline $\mathrm{CH} \# 3$ & 03 & 05 & 04 & 01 & - & - & 01 & 02 & 16 \\
\hline $\mathrm{CH} \# 4$ & 03 & 02 & 04 & - & - & 01 & - & 02 & 12 \\
\hline $\mathrm{CH} \# 5$ & - & 06 & 03 & - & 01 & 01 & - & 02 & 13 \\
\hline Total parcial & 08 & 22 & 23 & 01 & 05 & 03 & 01 & 17 & \\
\hline$\%$ & $15 \%$ & $42 \%$ & $42 \%$ & $3,7 \%$ & $18 \%$ & $11 \%$ & $3,7 \%$ & $62 \%$ & \\
\hline $\begin{array}{c}\text { Total } \\
\text { absoluto }\end{array}$ & \multicolumn{3}{|c|}{52} & \multicolumn{5}{|c|}{21} & 79 \\
\hline$\%$ & \multicolumn{3}{|c|}{$65 \%$} & \multicolumn{5}{|c|}{$34 \%$} & \\
\hline
\end{tabular}

Tabela 1 - Distribuição do Subsistema de Engajamento - Ciência Hoje - .

Essa predominância também pode ser observada nas notícias da GL: das 48 ocorrências do Subsistema de Engajamento, 56\% correspondem à expansão dialógica (Tabela 2).

\begin{tabular}{|c|c|c|c|c|c|c|c|c|c|}
\hline \multirow{3}{*}{ Galileu } & \multicolumn{3}{|c|}{ Expansão dialógica } & \multicolumn{5}{|c|}{ Contração dialógica } & \multirow{3}{*}{ ) } \\
\hline & \multirow[b]{2}{*}{ Acolher } & \multicolumn{2}{|c|}{ Atribuição } & \multicolumn{2}{|c|}{ Refutar } & \multicolumn{3}{|c|}{ Declarar } & \\
\hline & & Reconhecer & Distanciar & Negar & Contestar & Concorrer & Pronunciar & Endossar & \\
\hline GL\#1 & - & - & - & 01 & 01 & 01 & - & 03 & 06 \\
\hline GL\#3 & 03 & 03 & - & - & 01 & 01 & - & 01 & 09 \\
\hline GL\#4 & 04 & 02 & - & - & 02 & - & 01 & - & 09 \\
\hline$\%$ & $48 \%$ & $40 \%$ & $11 \%$ & $4.7 \%$ & $28 \%$ & $14 \%$ & $4.7 \%$ & $47 \%$ & \\
\hline $\begin{array}{c}\text { Total } \\
\text { absoluto }\end{array}$ & \multicolumn{3}{|c|}{27} & \multicolumn{5}{|c|}{21} & 48 \\
\hline$\%$ & \multicolumn{3}{|c|}{$56 \%$} & \multicolumn{5}{|c|}{$43 \%$} & \\
\hline
\end{tabular}

Tabela 2 - Distribuição do Subsistema de Engajamento - Galileu -.

Por fim, na SCIAMB, a expansão dialógica também é predominante: das 38 ocorrências, $56 \%$ dizem respeito a essa orientação (Tabela 3).

Cadernos do IL. Porto Alegre, n. ${ }^{\text {o } 38, ~ j u n h o ~ d e ~ 2009 . ~ p . ~ 155-165 . ~}$

http://www.seer.ufrgs.br/cadernosdoil/ 


\begin{tabular}{|c|c|c|c|c|c|c|c|c|c|}
\hline \multirow{3}{*}{$\begin{array}{c}\text { Scientific } \\
\text { America } \\
\text { Brasil }\end{array}$} & \multicolumn{3}{|c|}{ Expansão dialógica } & \multicolumn{5}{|c|}{ Contração dialógica } & \multirow{3}{*}{ 唁 } \\
\hline & \multirow[b]{2}{*}{ Acolher } & \multicolumn{2}{|c|}{ Atribuição } & \multicolumn{2}{|c|}{ Refutar } & \multicolumn{3}{|c|}{ Declarar } & \\
\hline & & Reconhecer & Distanciar & Negar & Contestar & Concorrer & Pronunciar & Endossar & \\
\hline SCIAM\#2 & 02 & 04 & 01 & - & 01 & - & - & 01 & 09 \\
\hline SCIAM\#3 & 02 & 02 & 03 & - & - & - & 01 & 01 & 09 \\
\hline SCIAM\#4 & 04 & 04 & 01 & - & - & - & 01 & - & 10 \\
\hline Total parcial & 12 & 10 & 08 & 0 & 01 & 0 & 05 & 02 & \\
\hline$\%$ & $40 \%$ & $33 \%$ & $26 \%$ & $0 \%$ & $22 \%$ & $0 \%$ & $55 \%$ & $22 \%$ & \\
\hline $\begin{array}{c}\text { Total } \\
\text { absoluto }\end{array}$ & \multicolumn{3}{|c|}{30} & \multicolumn{5}{|c|}{08} & 38 \\
\hline$\%$ & \multicolumn{3}{|c|}{$56 \%$} & \multicolumn{5}{|c|}{$21 \%$} & \\
\hline
\end{tabular}

Tabela 3 - Distribuição do Subsistema de Engajamento - Scientific American Brasil -.

A predominância dos sentidos que constroem a expansão dialógica demonstra uma maximização do espaço dialógico nas notícias analisadas. Vozes externas, projetadas por processos verbais que dificultam a identificação do posicionamento da voz autoral sobre o conteúdo das projeções, são chamadas para avaliar e explicar o assunto em pauta na notícia. O discurso é modalizado: evitam-se declarações de caráter assertivo, as proposições são apresentadas como mais ou menos prováveis, criando um espaço para posicionamentos alternativos e produzindo efeitos de impessoalidade e imparcialidade em relação aos valores expressos pelo conteúdo reportado nas notícias.

Embora predomine a expansão dialógica nas notícias das três revistas, verificamos diferenças em suas variáveis de ocorrência. Nas notícias da $\mathrm{CH}$, são recorrentes a atribuição por reconhecimento e a atribuição por distanciamento (Tabela 1). Os exemplos 1 e 2 ilustram a ocorrência dessas duas subcategorias (itálico) nas notícias do corpus.

Exemplo 1

$\mathrm{CH} \# 2$ A cientista acredita, porém, que os organismos podem contribuir para o desenvolvimento de doenças infecciosas e crônicas tanto em fumantes ativos quanto passivos.

CH\#3 Segundo Miyake, ainda não há previsão de quando serão iniciados testes com humanos para tratamento de tumores cerebrais com AGL. Ele conta que esse ácido graxo tem um efeito colateral sobre a quantidade de lipídios que favorecem um processo de inflamação no cérebro.

Exemplo 2

CH\#3 "Esse é um tempo bastante curto", avalia Miyake em entrevista à $\mathrm{CH}$ On-line. "Há inclusive estudos em cultura com outros tipos de câncer nos quais se observa diferença na proliferação das células tumorais em apenas 24 horas", acrescenta.

Cadernos do IL. Porto Alegre, n. ${ }^{\text {o } 38, ~ j u n h o ~ d e ~ 2009 . ~ p . ~ 155-165 . ~}$

http://www.seer.ufrgs.br/cadernosdoil/ 
CH\#5 "Uma das principais utilidades deste diagnóstico é poder elaborar estratégias preventivas e de tratamento para uma população de risco, concentrando-se nos homens e jovens de grandes metrópoles", explica a psicóloga.

No exemplo 1, mostramos a ocorrência da atribuição por reconhecimento ilustrada pelos processos acredita e conta e pela circunstância de ângulo Segundo Miyake. No exemplo 2, verificamos a presença da atribuição por distanciamento; a voz autoral é separada diretamente do conteúdo da proposição da voz não autoral por meio do uso das aspas e com o processo posposto à declaração projetada na citação, distanciando-se da proposição e atribuindo, portanto, a responsabilidade pela veracidade e pela confiabilidade do conteúdo reportado à voz não autoral inserida na notícia. Diferentemente da $\mathrm{CH}$, na GL e na SCIAMB, os sentidos da expansão dialógica são construídos especialmente pelo acolhimento, seguido pela atribuição por reconhecimento (Tabelas 1 e 2). Os exemplos 3 e 4 ilustram a ocorrência dessas subcategorias (itálico) nessas revistas.

Exemplo 3

GL\#2 Como fugir dessa situação? Talvez oferecer um treino a funcionários promovidos, torcendo para que ele possa suprir alguma deficiência de habilidades.

GL\#4 Genes 'melhores' podem fazer mulher ter mais parceiros

SCIAMB\#4 Coração pode revelar informações sobre a saúde dos rins

Exemplo 4

GL\#2 Essa dificuldade crescente, de acordo com Pluchino, gera agressividade.

GL\#2 Uma promoção, diz o texto, traz maior responsabilidade e a necessidade de ser mais competente para atender às expectativas e demandas que o novo cargo exige.

SCIAM\#2 Segundo Roy-Byrne, os resultados mostraram como se poderia usar a tecnologia para tratar uma ampla gama de transtornos de ansiedade.

No exemplo 3, ilustramos a ocorrência da expansão dialógica por acolhimento, nas revistas GL e SCIAMB, por meio do emprego dos modais de probabilidade podem fazer e pode revelar, pelo uso de uma pergunta retórica Como fugir dessa situação? e pelo emprego do adjunto modal talvez. Neste trabalho, "pergunta retórica" é entendida como um enunciado interrogativo por meio do qual o interlocutor não interroga senão ficticiamente seu alocutário, sendo, portanto, desprovida de resposta, mas não impedindo uma réplica que pode confirmar ou infirmar as pressuposições lançadas pelo interlocutor (RAMOS, 1996). Assim, as perguntas retóricas expandem o espaço dialógico, na medida em que abrem espaço para outros posicionamentos e outras respostas sobre o conteúdo da proposição.

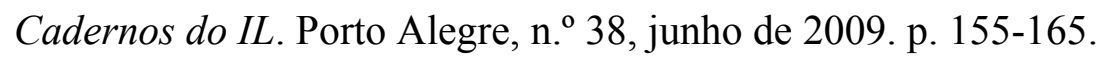


Através do emprego de modais de probabilidade, adjuntos modais e perguntas retóricas, a voz autoral procura diminuir o grau de comprometimento com o conteúdo de sua própria declaração, produzindo um efeito de suposição e expandindo o espaço dialógico para pontos de vistas alternativos.

No exemplo 4, ilustramos a ocorrência da atribuição por reconhecimento, na GL e na SCIAMB, pelo emprego das circunstâncias de ângulo de acordo com e segundo e o processo verbal diz.

Os sentidos da contração dialógica são construídos frequentemente pelo endosso nas revistas CH e GL (Tabelas 1 e 2). As proposições são introduzidas também por processos verbais e são construídas pela voz autoral como válidas, corretas e confiáveis, conforme demonstra o exemplo 5 (itálico).

Exemplo 5

CH\#3 Cientistas brasileiros confirmam eficácia da aplicação de um ácido graxo extraído de plantas na redução de tumores cerebrais em ratos (...)

CH\#5 Levantamento sobre consumo de drogas revela que 2,1\% da população brasileira usa maconha.

GL\#1 Estudo mostra que testosterona masculina aumenta ao sentir o cheiro natural de mulheres em período de ovulação

GL\#2 Pesquisas mostram que insegurança e falta de qualificação para o cargo podem levar a aumento de agressividade

No exemplo 5, as declarações projetadas pelos processos confirmam, revela, mostra e mostram sugerem a exclusão de outros posicionamentos alternativos. Assim, o espaço dialógico é reduzido. Diferentemente da expansão por atribuição, que emprega o relato e a citação para dissociar a proposição da voz não autoral, produzindo um efeito de imparcialidade, o emprego dos itens lexicais que constroem o endosso indica que a voz autoral se engaja com a voz não autoral, compartilhando a responsabilidade sobre a veracidade e a confiabilidade da declaração.

$\mathrm{Na}$ SCIAMB, entretanto, os sentidos da contração dialógica são construídos recorrentemente pelo pronunciamento, conforme ilustra o exemplo 6.

Exemplo 6

SCIAMB\#1 É possível ampliar em até mil vezes uma única célula pré-cancerosa

SCIAMB\#1 A terceira tecnologia - o sistema de endomicroscopia a laser com sonda (pCLE - probe-based confocal laser endomicroscopy) - é a tecnologia mais avançada no momento.

Cadernos do IL. Porto Alegre, n. ${ }^{\text {o } 38, ~ j u n h o ~ d e ~ 2009 . ~ p . ~ 155-165 . ~}$ 
SCIAMB\#2 O cigarro tem um papel indiscutível no desenvolvimento de câncer de pulmão.

SCIAMB\#4 Pessoas com elevada taxa de descanso do batimento cardíaco são mais propensas a doenças.

No exemplo 6, por meio do emprego das formulações é possível, é a tecnologia mais avançada, o cigarro tem e são mais propensas, podemos verificar a intervenção explícita da voz autoral para acentuar o valor ou a confiabilidade da informação. Essas formulações parecem ser empregadas como um registro de uma defesa para eliminar posicionamentos retóricos alternativos ou futuros que vão de encontro ao ponto de vista apresentado. Essa intervenção explícita da voz autoral pode estar relacionada ao fato de que, nessa revista, muitas vezes, o próprio pesquisador assume o papel de jornalista (TUCHERMAN; CAVALCANTI; OITICICA, 2010, p. 293), fazendo a mediação entre os resultados de sua pesquisa e a sociedade no geral e, assim, podendo fazer declarações mais categóricas sobre a pesquisa popularizada.

\section{CONSIDERAÇÕES FINAIS}

Nesta pesquisa de cunho qualiquantitativo, tivemos como objetivo analisar a configuração e a função do Subsistema de Engajamento em 15 notícias de popularização científica sobre tópicos de saúde, publicadas pelas revistas Ciência Hoje, Galileu e Scientific American Brasil. Os dados levantados indicam que predomina a expansão dialógica por meio das categorias de acolhimento, atribuição por reconhecimento e por distanciamento.

A retórica do discurso jornalístico, nas notícias analisadas, parece utilizar essas subcategorias para marcar a sua natureza impessoal, alcançada por meio da mobilização do relato, da citação e de modais de probabilidade, por exemplo, que sugerem uma tentativa de isenção de responsabilidade por parte da voz autoral em relação ao conteúdo das suas proposições e das proposições das vozes não autorias inseridas nas notícias. Ressaltamos que a diferença de frequência dos sentidos que constroem a expansão dialógica pode estar relacionada ao grau de cientificidade imprimido nesses textos, em termos de profundidade e de rigor de tratamento do tópico desenvolvido na pesquisa científica popularizada. A GL e a SCIAMB parecem se restringir a passar informações de modo neutro e objetivo. Diferentemente, a $\mathrm{CH}$ emprega mais frequentemente o relato e a citação, trazendo a voz do pesquisador que realizou o estudo popularizado como uma autoridade para explicar os fatos reportados, buscando o aprofundamento dos fenômenos científicos abordados nas notícias. 


\section{REFERÊNCIAS}

BAKHTIN, Mikhail. Marxismo e filosofia da linguagem. 11 ed. São Paulo: Hucitec, 2004.

CABRAL, Sara; BARROS, Nina. Linguagem e avaliação: uma análise de texto opinativo. In: International Systemic Functional Congress, XXXIII, jul. 2006, São Paulo, SP. Proceedings. São Paulo, SP: LAEL-PUC-SP, 2006, p. 722-734.

MARTIN, Jim; WHITE, Peter. The language of evaluation: appraisal in English. New York, NY/USA: Palgrave, 2005.

MOTTA-ROTH, Désirée. Análise crítica de gêneros com foco em artigos de popularização da ciência. Projeto de Produtividade em Pesquisa PQ/CNPq ( ${ }^{\circ}$. 301962/2007-3), 2007.

MOTTA-ROTH, Desirée; MARCUZZO, Patrícia. Ciência na mídia: análise crítica de gênero de notícias de popularização científica. Revista Brasileira de Linguística Aplicada. Belo Horizonte, v. 10, n. 3, p. 511-538, mar. 2009.

MOTTA-ROTH, Désirée; LOVATO, Cristina dos Santos. O poder hegemônico da ciência no discurso de popularização científica. Calidoscópio. São Leopoldo, no prelo.

RAMOS, Rui. Estratégias argumentativas: as perguntas retóricas. In: ABREU, Luís Machado de (org.). Diagonais das Letras Portuguesas Contemporâneas. Actas do $2^{\circ}$ Encontro de Estudos Portugueses. Aveiro, p. 171-186, nov.1996,

TUCHERMAN, Ida; CAVALCANTI, Cecilia; OITICICA, Luiza. Revistas de divulgação científica e ciências da vida: encontros e desencontros. Intercom - Revista Brasileira de Ciências da Comunicação. São Paulo, v.33, n.1, p. 277-295, jan./jun. 2010. 